\title{
The correlation of caregiving burden with depression, anxiety, and stress among caregivers of people with schizophrenia
}

I Kadek Suaryana,

Cokorda Bagus Jaya Lesmana, Luh Nyoman Alit Aryani

Department of Psychiatry, Faculty of Medicine Udayana University/Sanglah General Hospital Bali, Indonesia

\section{Cite this article:}

Suryana IK, Lesmana CBJ, Aryani LNA. The correlation of caregiving burden with depression, anxiety, and stress among caregivers of people with schizophrenia. Journal of Clinical and Cultural Psychiatry. 2020; I (2): 2I-24.

Corresponding author:

Cokorda Bagus Jaya Lesmana Department of Psychiatry, Faculty of Medicine Udayana University/Sanglah General Hospital JI. Kesehatan No I, Bali 80I I4, Indonesia cokordabagus@unud.ac.id

\begin{abstract}
Background: Schizophrenia is a severe mental disorder that requires collaborative approach from the health care provider, family, and the society in its management. Adequate support from the family of people with schizophrenia plays a significant role in their recovery. However, providing support to these patients might become a significant burden among caregiver that it might induce the occurrence of stress, mood changes, and ansiety. This research aimed to determine the correlation between caregiver burden and the mental problems that might be experienced by caregivers of people with schizophrenia.

Patients and Methods: This qualitative research employed a cross sectional analytic design. Samples were obtained consecutively in June and July 2018. The questionnaires used were the 22 item Zarit Burden Interview (ZBI) and the 42 item Depression, Anxiety and Stress Scale (DASS-42).

Result: A number of 69 subjects participated. The caregiving burden demonstrated strong positive significantly correlations with problems including depression, anxiety, and stress ( $\mathrm{r}=0.618$, $\mathrm{r}=0.694, \mathrm{r}=0.808$, respectively ; all $\mathrm{p}<0.001$ ).
\end{abstract}

Conclusion: There is a relationship between caregiving burden and depression, anxiety, and stress on caregivers of people with schizophrenia (PWS) in Sanglah Hospital in Denpasar.

Keywords: caregiving burden, depression, anxiety, stress

\section{Introduction}

Schizophrenia is characterized by loss of touch to reality, distortion or disorganization of mental capacity, and the capacity of the individual to recognize reality, communicate, and form relationships with others. ${ }^{1}$ Characteristics of schizophrenia tend to be associated with chronic impairment and the characteristics of psychotic episodes that could have an impact not only on the patient but also on the people around them, especially those closest. These closest people usually involved as caregivers for patients and help patients. ${ }^{2}$

Family involvement in patients with schizophrenia will appear very clear in those who experience long-term impairment, but their involvement in the early stages of the disease is also essential. Providing family intervention at an early stage for both patient and caregiver is essential to help relatives to improve their understanding of the disease, addressing disrupted thought and emotion, reducing negative assessment, and prevent high emotional expression to the patient. ${ }^{3}$

Caregivers need special attention so that they can overcome difficulties and support the recovery of the patient. So far, not much is known of any research on caregivers of patients with schizophrenia in Indonesia. At Psychiatry Polyclinic of Sanglah General Hospital (RSUP) itself, 
from 3,536 the number of visits during 2017, there were about 850 visits by patients with the diagnosis of schizophrenia. So far, the burden of care on caregivers who accompany patients with schizophrenia and the possible relation with psychiatric problems such as depression, anxiety, and stress they might experience is not known, but it is vital to know in order to be intervened. Based on these considerations, the researcher has an interest in conducting this study.

\section{Material and Methods}

This study uses a quantitative analytical design with a cross-sectional analytic approach. This research was conducted in the Department of Psychiatry at the Sanglah Hospital for two months. Subjects were taken from caregivers of schizophrenia patients in Sanglah Hospital in Denpasar. The inclusion criteria are persons with schizophrenia caregivers who came to Sanglah General Hospital on 1st June to 31 st July 2018 , have a family member who is suffering from schizophrenia and living at the same home, and willing to participate in the study by signing informed consent. The exclusion criteria include caregivers who had expressed approval but withdrew consent in the middle of research, not living at the same home with the patient, have mental disorders, or are in the process of psychiatric treatment.

The data collection instrument in this study consists of primary data forms and two measuring devices. Basic data form included characteristics of the patient (diagnosis, treatment duration, number of psychotic episodes, sex, age, occupation, education) and caregiver characteristics (gender, age, education level, relationship with the patient). The caregiving burden was assessed with the Zarit Burden Interview (ZBI) scale, which includes 22 items. Depression, anxiety, and stress were measured with the Depression, Anxiety, Stress Scales (DASS-42). Data were analyzed with computer assistance using the Statistical Package for the Social Sciences (SPSS) 21st edition and displayed in the form of tables and narration.

\section{Result}

Sixty-nine respondents met the inclusion criteria for the sample used in this study. The mean age of the study subjects is 45 years old, with a standard deviation of 12.5 years. The characteristics of caregivers are presented in Table 1.

Table 1. Characteristics of the study subjects (caregivers).

\begin{tabular}{cl}
\hline Variables & $\mathrm{n}(\%)$ \\
\hline Age (years), mean \pm SD & $45 \pm 12.5$ \\
$<25$ & $2(2.9)$ \\
$25-44$ & $33(47.8)$ \\
$45-59$ & $20(29.0)$ \\
$\geq 60$ & $14(20.3)$ \\
Gender & $36(52.2)$ \\
Male & $33(47.8)$ \\
Woman & \\
Occupation & $68(98.6)$ \\
Work & $1(1.4)$ \\
Does not work & $1(1.4)$ \\
Education & $10(14.5)$ \\
Uneducated & $7(10.1)$ \\
Primary school & $33(47.8)$ \\
Junior high & $18(26.1)$ \\
High School & \\
University & $60(87.0)$ \\
Marital status & $9(13.0)$ \\
Married & \\
Not married / Divorced & $16(23.2)$ \\
Relationships with patients & $22(31.9)$ \\
Spouse & $17(24.6)$ \\
Biological parents & $4(5.8)$ \\
Siblings & $10(14.5)$ \\
Biological children & \\
Others &
\end{tabular}

Table 2 shows the characteristics of the patients treated. The average age of the patients of this study subjects is 35.9 years old. Patients tend to be younger than their caregivers. Based on the total treatment duration, 32 people $(46.4 \%)$ less than three years, and 37 people (53.6\%) is equal to 3 years. The number of psychotic episodes distributed one time as many as 25 people $(36.2 \%)$ and most often distributed as much as five times with four people (5.8\%).

Table 2. Characteristics of patients treated.

\begin{tabular}{|c|c|}
\hline Variables & $\mathrm{n}(\%)$ \\
\hline Age (years), mean \pm SD & $35.9 \pm 9.6$ \\
\hline$<25$ & $7(10.1)$ \\
\hline $25-44$ & $51(73.9)$ \\
\hline $45-59$ & $10(14.5)$ \\
\hline$\geq 60$ & $1(1.4)$ \\
\hline \multicolumn{2}{|l|}{ Gender } \\
\hline Male & $49(71.0)$ \\
\hline Woman & $20(29.0)$ \\
\hline \multicolumn{2}{|l|}{ Occupation } \\
\hline Work & $32(46.4)$ \\
\hline Does not work & $37(53.6)$ \\
\hline \multicolumn{2}{|l|}{ Education } \\
\hline Elementary & $6(8.7)$ \\
\hline Junior high & $11(15.9)$ \\
\hline High school & $41(59.4)$ \\
\hline University & $11(15.9)$ \\
\hline \multicolumn{2}{|l|}{ Marital status } \\
\hline Married & $26(37.7)$ \\
\hline Not married / divorced & $43(62.3)$ \\
\hline \multicolumn{2}{|l|}{ Diagnosis } \\
\hline Paranoid schizophrenia & $50(72.5)$ \\
\hline Hebephrenic schizophrenia & $13(18.8)$ \\
\hline Catatonic schizophrenia & $6(8.7)$ \\
\hline \multicolumn{2}{|l|}{ Duration of treatment } \\
\hline$<3$ years & $32(46.4)$ \\
\hline$\geq 3$ years & $37(53.6)$ \\
\hline \multicolumn{2}{|l|}{ Number of psychotic episode } \\
\hline 1 & $25(36.2)$ \\
\hline 2 & $20(29.0)$ \\
\hline 3 & $17(24.6)$ \\
\hline 4 & $3(4.3)$ \\
\hline$>5$ & $4(5.8)$ \\
\hline
\end{tabular}

Table 3. Overview assessment of caregiving burden and DASS-42.

\begin{tabular}{ll}
\hline Variables & $\mathrm{n}(\%)$ \\
\hline Score of caregiving burden, median (min-max) & $23(4-47)$ \\
Category of caregiving burden & \\
None & $25(36.2)$ \\
Mild & $39(56.5)$ \\
Moderate & $5(7.3)$ \\
Depression score, median (min-max) & $5(0-16)$ \\
Category of depression & \\
Normal & \\
Mild & $50(72.5)$ \\
Moderate & $8(11.6)$ \\
Anxiety score, median (min-max) & $11(15.9)$ \\
Category of anxiety & $3(0-19)$ \\
Normal & \\
Mild & $57(82.6)$ \\
Moderate & $4(5.8)$ \\
Severe & $7(10.1)$ \\
Stress score, median (min-max) & $1(1.4)$ \\
Category of stress & $7(0-20)$ \\
Normal & \\
Mild & $58(84.1)$ \\
Moderate & $9(13.0)$ \\
& $2(2.9)$ \\
\hline
\end{tabular}

As shown on the table, the category of the caregiving burden are moslty classified as mild caregiving burden with 39 people (56.5\%), 25 people (36.2\%) even have no burden, the rest is only 5 people (7.3\%) with moderate caregiving burden. Depression score rate of research subjects with median score of 5 with minimum score of 0 and maximum score of 16 . Based on that score category as many as 50 people $(72.5 \%)$ is normal or not depressed. 8 people $(11.6 \%)$ have 
mild depression, and 11 people (15.9\%) have moderate depression. Assessment of anxiety obtained a median score of 3 with the lowest score is the highest score of 0 and 19. Category of anxiety varies from normal to severe anxiety. However most are classified as normal with 57 people (82.6\%), 4 people $(5.8 \%)$ are mild, 7 people $(10.1 \%)$ are moderate and 1 person $(1.4 \%)$ is severe. Distribution of stress category are mostly normal with 58 people (84.1\%), 9 people (13.0\%) are mild and 2 people $(2.9 \%)$

Table 4. Correlation between caregiving burden score and DASS-42.

\begin{tabular}{|c|c|c|c|c|c|}
\hline \multirow[t]{2}{*}{$\overline{\text { Variables }}$} & $\mathrm{D}$ & \multicolumn{2}{|c|}{$\mathrm{A}$} & \multicolumn{2}{|c|}{$\mathrm{S}$} \\
\hline & $\mathrm{p}$ value & $\mathrm{r}$ & $\mathrm{p}$ value & $\mathrm{r}$ & $\mathrm{p}$ value \\
\hline Caregiving burden score & $0.618<0.001$ & 0.694 & $<0.001$ & 0.808 & $<0.001$ \\
\hline
\end{tabular}

Table 4 shows a strong positive correlation between the score of caregiving burden and depression score, the higher the caregiving burden the higher the level of depression. Caregiving burden score and anxiety scores obtained correlation coefficient of 0.694 and $p$ $<0.001$, which means there is a strong positive correlation between score of caregiving burden and score of anxiety. Likewise, the correlation between score of caregiving burden and stress scores even higher correlation coefficient of 0.808 and $p<0.001$, which means there is a very strong positive correlation between the score of caregiving burden and stress.

Table 5. Distribution of depression level based on the level of caregiving burden.

\begin{tabular}{cllll}
\hline Variables & \multicolumn{3}{c}{ Depression level } & \\
\cline { 2 - 4 } \multicolumn{1}{c}{ Level of caregiving burden } & \multicolumn{1}{c}{ Normal } & Mild & Moderate & p value \\
None/almost none & $24(96.0)$ & $1(4.0)$ & $0(0.0)$ & \\
Mild & $26(66.7)$ & $6(15.4)$ & $7(17.9)$ & $<0.001^{\alpha}$ \\
Moderate & $0(0.0)$ & $1(20.0)$ & $4(80.0)$ & \\
\hline a & & &
\end{tabular}

Likelihood-ratio test

Table 5 shows that caregivers with none or almost none caregiving burden are mostly $96.0 \%$ have normal level of depression (no depression), only one person suffered mild depression. Mostly $66.7 \%$ with mild caregiving burden have normal level of depression, $15.4 \%$ have mild depression and $17.9 \%$ have moderate depression with mild caregiving burden. Among moderate caregiving burden none is depressed (normal), 1 person (20.0\%) experienced mild depression and 4 people $(80 \%)$ with moderate depression. The higher level of caregiving burden, the higher the chance to experience levels of depression.

Table 6. Distribution of anxiety level based on the level of caregiving burden.

\begin{tabular}{llllll}
\hline Variables & \multicolumn{4}{c}{ Anxiety level } & \\
\cline { 2 - 5 } & Mild & Moderate & Severe & Normal & p value \\
\hline Level of caregiving burden & & & & & \\
None/almost none & $25(100)$ & $0(0.0)$ & $0(0.0)$ & $0(0.0)$ & \\
Mild & $30(76.9)$ & $3(7.7)$ & $6(15.4)$ & $0(0.0)$ & $0.006^{a}$ \\
Moderate & $2(40.0)$ & $1(20.0)$ & $1(20.0)$ & $1(20.0)$ & \\
\hline Likelihood-ratio test & & & & &
\end{tabular}

Likelihood-ratio test

Tables 6 and 7 show the distribution of anxiety level based on the level of caregiving burden. At none/almost none level of caregiving burden none experience anxiety or $100 \%$ normal. While at mild caregiving burden some starts experiencing mild anxiety with 3 people (7.7\%) and moderate enxiety with 6 people (15.4\%).

Table 7. Distribution of stress level based on the level of caregiving burden.

\begin{tabular}{|c|c|c|c|c|}
\hline \multirow[t]{2}{*}{ Variables } & \multicolumn{3}{|c|}{ Stress level } & \multirow[b]{2}{*}{$\mathrm{p}$ value } \\
\hline & Normal & Mild & Moderate & \\
\hline \multicolumn{5}{|c|}{ Level of caregiving burden } \\
\hline None & $25(100)$ & $0(0.0)$ & $0(0.0)$ & \\
\hline Mild & $33(84.6)$ & $6(15.4)$ & $0(0.0)$ & $<0.001^{\alpha}$ \\
\hline Moderate & $0(0.0)$ & $3(60.0)$ & $2(40.0)$ & \\
\hline
\end{tabular}

At the level of moderate caregiving burden only 2 people (40.0\%) are normal, while each 1 person (20\%) has mild, moderate and severe anxiety. Six people (15.4\%) with mild caregiving burden experiences mild stress. At the level moderate caregiving burden mostly have mild stress with 3 people $(60 \%)$ and 2 people (40\%) have moderate stress. While the $\mathrm{p}$ value of $<0.001$ showing significant results.

\section{Discussion}

The results show that the age of caregivers in schizophrenic patients is mostly adulthood and productive age group between 25 years-44 years with a total of 33 respondents $(47.8 \%)$. That age is mature enough to make decisions, able to think rationally, and to control emotions. This age is also considered mature enough in life and mental experience to take care of a family member who has schizophrenia. $^{4}$

The sex majority of caregivers in this study is male, with 36 respondents $(52.2 \%)$. This is not following the majority of Indonesian people who usually put women to take care of the household, including caring for a sick family member. This is due to women's social role and hormonal factors. Women are more dominant primary caregivers compared to men. This study found as many as $56.5 \%$ of respondents with mild care treatment burden, and five respondents with moderate caregiving burden, the rest with no caregiving burden. Most respondents experienced caregiving burden. Respondents as caregivers are a primary source of support and often manage the economy, medical assistance, and supervision for everyday tasks. Meeting the physical and psychological needs of the PWS, spending 6-9 hours per day to provide care and attention. ${ }^{5}$

Only a small part have depression, anxiety, and stress. This is because caregivers can take care the patients with the motivation and sense of responsibility to perform the duty or simply because there is a desire to do good. Normally this can happen in families that show good relationships and flexibility, used to open communication, and is able to use more resources in the community to solve the problem. ${ }^{6}$

In this study, there's correlation between the score of caregiving burden and DASS-42. Strong positive correlation between the score of caregiving burden and depression scores showed that the higher the caregiving burden, the higher the level of depression. Likewise, there is a strong positive correlation between the score of caregiving burden and score of anxiety. The higher the score caregiving burden, 
the higher the anxiety score. In contrast to the correlation between the score of caregiving burden and stress score is even a very strong positive correlation between the score of caregiving burden and stress score. The relationship between caregiving burden and DASS-42 also considered other variables that may be associated with DASS-42. For example, the number of recurrence psychotic episodes has meaningful relationship. With higher psychotic episodes, the caregiving burden for caregivers will increase.

The benefits of this research is the need of more specific treatment for families who take care of people with schizophrenia. In outpatient setting, beside management of outpatient patients, intervention of medical personnel to the caregiver should also be done. These interventions include the provision of information and understanding about various things about the disease such as: the cause of disease, symptoms occuring, behavior may be caused, course of the disease, functional and social barriers that may occur, handling of the crisis and the importance of medication adherence. The importance of the support of other family members in the care of the patient also needs to be emphasized.

The weakness of this study is that component of caregiving burden was assessed at one time so it couldn't be seen in depth. More in-depth observation study is needed to determine caregiving burden experienced by families who care for people with schizophrenia.

\section{Conclusion}

Most caregivers of people with schizophrenia in Sanglah Hospital are categorized as having caregiving burden. From this study we can conclude that there is a relationship between caregiving burden and depression, anxiety, and stress on caregivers of people with schizophrenia (PWS) in Sanglah Hospital in Denpasar. Under these conditions, psychosocial interventions to families who care for people with schizophrenia is an important thing. Support for caregivers also need to be emphasized in the treatment of schizophrenic patients while not ignoring the mental health problems of caregivers.

\section{Acknowledgement}

The authors report no conflict of interests.

\section{Reference}

1. Suryani LK, Lesmana CBJ, Tiliopoulos N. Treating the untreated: Applying a community-based, culturally sensitive psychiatric intervention to confined and physically restrained mentally ill individuals in Bali,
Indonesia. Eur Arch Psychiatry Clin Neurosci. 2011;261(Suppl 2):S1404. DOI: 10.1007/s00406-011-0238-y

2. Sadath A, Muralidhar D, Varambally S, et al. Do stress and support matter for caring? The role of perceived stress and social support on expressed emotion of carers of persons with first episode psychosis. Asian J Psychiatr. 2017;25:163-168. DOI: 10.1016/j.ajp.2016.10.023

3. Domínguez-Martínez T, Medina-Pradas C, Kwapil TR, et al. Relatives' expressed emotion, distress and attributions in clinical high-risk and recent onset of psychosis. Psychiatry Res. 2017;247:323-329. DOI: 10.1016/j.psychres.2016.11.048

4. Lippi G. Schizophrenia in a member of the family: Burden, expressed emotion and addressing the needs of the whole family. South African $J$ Psychiatry. 2016;22(1):922. DOI: 10.4102/sajpsychiatry.v22i1.922

5. Chen D, Guo X, Zheng Z, et al. Depression and anxiety in amyotrophic lateral sclerosis: Correlations between the distress of patients and caregivers. Muscle and Nerve. 2015;51(3):353-357. DOI: 10.1002/ mus. 24325

6. Van As N, Janssens J. Relationships between child behavior problems and family functioning: A literature review. Int $J$ Child Fam Welf. 2002;5(1):40-51.bridge : MA, Harvard University Press, 1999:314. 